\title{
New combination treatments in the management of asthma: focus on fluticasone/vilanterol
}

This article was published in the following Dove Press journal:

Journal of Asthma and Allergy

3 May 2014

Number of times this article has been viewed

\author{
Laren D Tan ${ }^{1,2}$ \\ Andrew L Chan ${ }^{1,2}$ \\ Timothy E Albertson ${ }^{1-3}$ \\ 'Division of Pulmonary, Critical Care \\ and Sleep Medicine, Department of \\ Internal Medicine, School of Medicine, \\ University of California, Davis, \\ Sacramento, CA, ${ }^{2}$ Department of \\ Medicine, Veterans Administration \\ Northern California Health Care \\ System, Mather, CA, ${ }^{3}$ Department \\ of Emergency Medicine, School of \\ Medicine, University of California, \\ Davis, Sacramento, CA, USA
}

\begin{abstract}
Despite the 2007 National Asthma Education and Prevention Program Expert Panel 3 guidelines for the treatment of uncontrolled asthma, many patients with poorly controlled asthma still continue to tax the health care system. Controlling asthma symptoms and preventing acute exacerbations have been the foundation of care. Using long-term controller treatments such as inhaled corticosteroids (ICS) and inhaled long-acting beta2-agonists (LABAs) is a common approach. While patient responses to recommended pharmacotherapy may vary, poor adherence to therapy also contributes to poor asthma control. A once-daily combination inhaler, such as fluticasone furoate, an ICS, in combination with vilanterol, a LABA, offers increased convenience and potential improved adherence, which should result in enhanced clinical outcomes and reduced exacerbations. The ICS/LABA combination inhaler of fluticasone furoate and vilanterol is currently approved in the United States for use in the maintenance of chronic obstructive pulmonary disease and to reduce exacerbations. This paper reviews the expanding literature on the efficacy of fluticasone furoate and vilanterol in treating asthma.
\end{abstract}

Keywords: inhaled corticosteroids (ICS), long-acting beta2-agonist (LABA), asthma treatments

\section{Introduction}

The prevalence of asthma ranges from $9.3 \%$ in children younger than 18 years to $7.3 \%$ among adults, with an incremental cost due to asthma of $\$ 56$ billion in the United States in 2007. ${ }^{1}$ Asthma medication compliance or adherence is often poor and is a significant contributor to poor health outcomes. Many factors can contribute to medication nonadherence in asthma, including economics, social and cultural barriers, attitude, and physician behavior. ${ }^{2}$ When pharmacy records are compared to patient interview data in older patients on medication use, kappa statistics range from 0.37 to 0.86 for chronic agreement between history and drug use records. ${ }^{3}$ History is not completely reliable as the sole means of measuring medication adherence.

In reviewing the impact of medication regimens on adherence to chronic treatments, Ingersoll and Cohen specifically noted the importance of dose frequency and regimen complexity as important factors. ${ }^{4}$ Coleman et al, in a meta-analysis evaluating medication use in chronic disease, reported that once-daily dosing had the best adherence while twice-a-day dosing reduced adherence by $6.7 \% .{ }^{5}$ Because of the importance of dosing frequency in asthma treatment, this paper reviews the potential use of a new inhaled cortical steroid (ICS)/long-acting beta2-agonist (LABA) (fluticasone furoate $[\mathrm{FF}] /$ vilanterol [VI]) combination dry-powder inhaler in the treatment of asthma.
Division of Pulmonary, Critical Care and Sleep Medicine, Department of Internal Medicine, PSSB 3400, 4150 V Street, Sacramento, CA 95817, USA

$\mathrm{Tel}+\mathrm{I} 9167343564$

$\mathrm{Fax}+19167347924$

Email tealbertson@ucdavis.edu 


\section{ICS in asthma}

ICS continue to be the preferred initial controller agent in persistent asthma and play an important role in the treatment of both chronic obstructive pulmonary disease (COPD) and asthma-COPD overlap syndrome (ACOS). ${ }^{6,7}$ The National Asthma Education and Prevention Program Expert Panel 3 asthma guidelines ${ }^{8,9}$ and various reviews have focused on the importance of ICS therapy in the maintenance treatment of patients with persistent asthma and ACOS. ${ }^{7,10}$ The anti-inflammatory actions of glucocorticoids in asthma are believed to be a result of direct inhibition of multiple cell types involved in airway inflammation (eg, mast cells, eosinophils, basophils, and lymphocytes) and of inflammatory mediators produced by these cells (eg, histamine, leukotriene, and cytokines) as part of the asthmatic response. ${ }^{11}$ The mechanism of action is thought to involve binding of corticosteroids to the glucocorticoid receptor, inducing a conformational change that allows the activated glucocorticoid receptor to bind to deoxyribonucleic acid (DNA). This binding occurs at the glucocorticoid-responsive DNA sequence that, subsequently, promotes synthesis of anti-inflammatory proteins and inhibition of transcription of many proinflammatory cytokines. ${ }^{12}$

Currently available ICS products include dry powder, liquid for nebulization, or metered-dose inhaler delivery systems. Assessing individual response to ICS products can be difficult because significant response variability has been reported with ICS use in persistent asthma and ACOS patients. ${ }^{7,13}$ The Predicting Response to Inhaled Corticosteroid Efficacy (PRICE) study demonstrated that short-term response to ICS predicts long-term asthma efficacy, but that as many as $40 \%$ of the patients were ICS nonresponders. ${ }^{14}$ A systematic review of current ICS-alone products failed to show an economic benefit from one product compared to other similar products. ${ }^{15}$

FF is currently available as an inhaled dry powder with once-daily dosing. In a randomized, double-blind, crossover design study of 190 patients aged $\geq 12$ years with persistent moderate asthma, patients were given either dry-powder inhalations of FF $200 \mu \mathrm{g}$ or fluticasone propionate (FP) $200 \mu \mathrm{g}$ once daily, FF $100 \mu \mathrm{g}$ or FP $100 \mu \mathrm{g}$ twice daily, or a matching placebo, for 28 days. Patients treated with the once-a-day or twice-a-day FP or FF demonstrated superior lung function compared to those on placebo. ${ }^{16}$ The absolute mean differences in forced expiratory volume in 1 second $\left(\mathrm{FEV}_{1}\right)$ from placebo were $108 \mathrm{~mL}$ (95\% confidence interval [CI]: 64-153; $P \leq 0.001)$ for FF $200 \mu \mathrm{g}$ daily; $98 \mathrm{~mL}$ (95\% CI: 54-142; $P \leq 0.001)$ for FF $100 \mu \mathrm{g}$ twice daily; $87 \mathrm{~mL}$ (95\% CI: 14-161; $P=0.020)$ for FP $200 \mu \mathrm{g}$ daily; and $132 \mathrm{~mL}$ (95\% CI: 59-205; $P \leq 0.001)$ for FP $100 \mu \mathrm{g}$ daily. The least effective treatment was FP $200 \mu \mathrm{g}$ once daily, supporting its currently approved twice-daily dosing interval. The use of FF $200 \mu \mathrm{g}$ once daily was not inferior to FF $100 \mu \mathrm{g}$ twice daily. ${ }^{16}$

An 8-week multicenter, double-blind, randomized study of 627 patients with persistent moderate-to-severe asthma evaluated placebo and FF 200, 400, 600, or $800 \mu \mathrm{g}$ dry-powder inhalation once daily or FP $500 \mu \mathrm{g}$ twice daily. ${ }^{17}$ There was no dose-response relationship seen in peak expiratory flow (PEF) in the FF doses studied, and all the doses of FF or FP were more effective $(P<0.001)$ than placebo. ${ }^{17}$ Improvement in PEF was significantly greater $(P<0.001)$ compared to placebo in all active groups, with a $5.1 \mathrm{~L} /$ minute decrease seen with placebo and a $16.3 \mathrm{~L} /$ minute increase with FF $800 \mu \mathrm{g}$; a 14.5 L/minute increase with FF $400 \mu \mathrm{g}$; and from 11.1 to 11.9 $\mathrm{L} /$ minute increases for the other FF and FP groups. The predefined $200 \mathrm{~mL} \mathrm{FEV}_{1}(P<0.001)$ improvement over placebo was confirmed for each dose of FF and FP at week $8 .{ }^{17}$

In another study, 575 patients with persistent asthma were randomized to inhaled dry-powder FF $100 \mu \mathrm{g}$ daily (morning), FF $100 \mu \mathrm{g}$ daily (evening), FF $250 \mu \mathrm{g}$ daily (evening), or placebo in a double-blind, double-dummy, placebo-controlled, parallel-group study. ${ }^{18}$ The greatest improvement in PEF was with the FF $250 \mu \mathrm{g}$ dose, but this was a small difference compared to either of the two daily FF $100 \mu \mathrm{g}$ doses (evening or morning). The change from baseline in trough PEF compared to placebo was an increase of $19.2 \mathrm{~L} / \mathrm{minute}$ (95\% CI: 8.2-30.2; $P<0.001$ ) for FF 100 $\mu \mathrm{g}$ (morning dose); an increase of $15.9 \mathrm{~L} /$ minute $(95 \% \mathrm{CI}$ : 4.9-26.9; $P=0.005$ ) for FF $100 \mu \mathrm{g}$ (evening dose); and an increase of $24.64 \mathrm{~L} /$ minute (95\% CI: $13.6-35.7 ; P<0.001$ ) for FF $250 \mu \mathrm{g}$ (evening dose). All of the FF doses demonstrated significantly better PEF than placebo. ${ }^{18}$

Taken together, the above data support the use of inhaled FF in the treatment of persistent moderate-to-severe asthma.

\section{LABAs}

Inhaled LABAs play an important role in providing bronchodilation in many patients suffering from asthma, COPD, or ACOS. Controversy exists about the use of inhaled LABAs when prescribed as monotherapy in persistent asthma. Chronic high-dose exposure to $\beta 2$-adrenoceptor agonists demonstrates proinflammatory effects. ${ }^{19}$ In vitro, they enhance the type 2 helper T-cell (TH2) inflammatory pathway by inhibiting interleukin-12 and interferon gamma. ${ }^{19,20}$ The US Food and Drug Administration (FDA), in 2010, performed its own meta-analysis examining inhaled LABA therapy use in asthma without simultaneous use of ICS compared to non-LABA therapy. ${ }^{21}$ According to this 
meta-analysis, the FDA estimated that 3.63 per 1,000 more clinical trial patients treated with the inhaled LABA had significant asthma-related events, including death, the need for intubation, or the need for hospitalization. ${ }^{21}$ When the inhaled LABA was paired with an ICS, the asthma-related event difference was a nonsignificant increase of 0.25 per 1,000 clinical trial patients. As a result, the FDA placed a "black box warning" to discontinue the use of LABAs in asthma as monotherapy and to remove LABA use in stable asthmatics, but they did not advise against continued use of LABA therapy with an ICS in persistent symptomatic asthma patients. ${ }^{21}$ The risks of LABA therapy in asthma patients was felt to be counterbalanced by the meaningful clinical symptomatic improvements seen when LABAs were added to ICS therapy. Inhaled LABAs remained the preferred add-on drug to ICS in the 2007 National Asthma Education and Prevention Program Expert Panel Report when ICS alone are ineffective in achieving asthma control. ${ }^{9}$ Table 1 summarizes currently available combined ICS + LABA preparations.

Available $\beta 2$-agonist bronchodilators act on $\beta 2$ airway receptors to cause relaxation of airway smooth muscles and improve airflow, thereby decreasing lung hyperinflation. The presumed mechanism of cellular action is through the stimulated receptors' ability to modulate intracellular adenylyl cyclase resulting in the generation of cyclic adenosine monophosphate (cAMP). The cAMP then results in the activation of effector protein kinases and guanine nucleotide exchange functions. ${ }^{22}$ The mechanism for the longer duration of action of LABAs is not known, but may be due to their greater lipophilicity, agonist efficacy, and microkinetic behaviors. ${ }^{22-24} \mathrm{VI}$ is a new potent, selective LABA with longer duration and greater intrinsic efficacy than salmeterol (SAL) and a greater potency than indacaterol and salbutamol. ${ }^{25}$ In addition, VI has been shown, using human recombinant $\beta 1 / 2 / 3$-adrenoreceptor cAMP assays, to have significantly greater $\beta 2$-adrenoceptor selectivity (versus $\beta 1$ or $\beta 3$ receptors) than formoterol, indacaterol, and salbutamol. ${ }^{26}$ In studies in patients with persistent asthma, inhaled VI in daily doses of $25-100 \mu \mathrm{g}$ dry powder was shown to have significant bronchodilation effects and to be well tolerated. ${ }^{27}$ In a double-blind, placebo-controlled 28-day trial of inhaled VI $(3,6.25,12.5,25$, and $50 \mu \mathrm{g})$ daily in persistent asthma patients, statistically significant $(P \leq 0.016)$ increases in morning $\mathrm{FEV}_{1}$ were reported for VI doses of $12.5-50 \mu \mathrm{g} .{ }^{25}$

Systematic reviews have shown that adding a LABA to low-dose ICS in poorly controlled asthma patients is more effective in reducing the risk of asthma exacerbations than using higher doses of ICS. ${ }^{28}$ Asthma patients controlled with low-dose ICS therapy who are then switched to either a LABA or placebo alone were shown to have more treatment failures and asthma exacerbations than those left on low-dose ICS. Both active treatments were superior to placebo. ${ }^{29}$ The use of combined ICS/LABA products was evaluated in a systematic and economic review. ${ }^{15}$ Cost savings were shown when using the combined products compared to the use of individual LABA and ICS inhalers. The review was unable to show a difference in asthma patients between combined $\mathrm{FP}+\mathrm{SAL}$ versus budesonide + formoterol inhalers.

Adherence with prescribed ICS therapy has been studied, with compliance rates ranging from only $30 \%$ to $70 \%{ }^{30-33}$ Low adherence is one of the major barriers to achieving asthma control and may also be associated with increased adverse outcomes. Many factors contribute to poor patient medication adherence, including cost, language, socioeconomic status, cultural, and insurance barriers; physician attitudes and behaviors; and patient health literacy and disease/ treatment understanding. ${ }^{2}$ A systematic review of 51 studies of medication adherence in various chronic diseases found that the prescribed daily frequency of dosing was a major predictor of adherence, with a $6.7 \%, 13.5 \%$, and $19.2 \%$ reduction in medication adherence when once-a-day dosing was compared to twice-daily, three-times daily, and fourtimes daily dosing, respectively. ${ }^{5}$ Another review of medication adherence in chronic disease found that dose-frequency medication regimen complexities are important factors. ${ }^{4}$ Using electronic ICS actuation counters, Onyirimba et $\mathrm{al}^{32}$ reported that control subjects used their ICS medications only $51 \%$ of the time and that the frequency of use decreased

Table I Currently available ICS/LABA inhalers

\begin{tabular}{|c|c|c|c|}
\hline Drugs: ICS + LABA & Type & Frequency & FDA approved \\
\hline Budesonide + formoterol fumarate & Inhalation/MDI/HFA & bid & $A, C$ \\
\hline Fluticasone propionate + salmeterol xinafoate & Inhalation/dry powder & bid & $\mathrm{A}, \mathrm{C}$ \\
\hline Fluticasone propionate + salmeterol xinafoate & Inhalation/MDI/HFA & bid & $A, C$ \\
\hline Mometasone furoate + formoterol fumarate & Inhalation/MDI/HFA & bid & A \\
\hline Fluticasone furoate + vilanterol trifenatate & Inhalation/dry powder & qd & C \\
\hline
\end{tabular}

Abbreviations: ICS, inhaled corticosteroid; LABA, long-acting beta2-agonist; MDI, metered-dose inhaler; HFA, hydrofluoroalkane; bid, twice daily; qd, once daily; FDA, US Food and Drug Administration; A, asthma indication; C, COPD indication. 
during a 10-week study. The direct clinician-to-patient feedback group demonstrated adherence rates greater than $70 \%$ during the entire study. A recent review of nonadherence in patients whose asthma was difficult to control confirmed a nonadherence range between $30 \%$ and $70 \%$, with associated poor health outcomes. ${ }^{34}$ No single approach can correct nonadherence to chronic asthma medication use, but reducing the frequency of dosing is likely to improve adherence. By simplifying the dosing regimen, inhaled FF in combination with the LABA VI, administered once daily, may increase patient adherence, leading to favorable results. For this reason, there is much interest in this combination treatment for persistent asthma.

\section{Efficacy of FF and VI in COPD}

One of the mainstay pharmacotherapies for the treatment of COPD consists of ICS therapy in combination with LABAs, which, until recently, required twice-daily dosing. The novel once-daily dosing of FF $100 \mu \mathrm{g} / \mathrm{VI} 25 \mu \mathrm{g}$ combination drypowder inhaler is FDA-approved for use as a maintenance therapy for COPD. In a 4-week randomized, double-blind, placebo-controlled study, patients with moderate-to-severe COPD were treated with either placebo or FF/VI $400 \mu \mathrm{g} / 25 \mu \mathrm{g}$ once a day. Results for 60 patients (mean age of 64 years; FF/VI $\mathrm{n}=40$; placebo $\mathrm{n}=20$ ) showed the FF/VI group had statistically greater improvements compared to placebo in trough $\mathrm{FEV}_{1}$ (mean difference of $183 \mathrm{~mL}$ [95\% CI: 87-179]) and in the 0 - to 4-hour post-dose weighted mean $\mathrm{FEV}_{1}$ (mean difference of $236 \mathrm{~mL}$ [95\% CI: 154-319]). ${ }^{35}$ Two other multicenter, randomized, double-blind, placebo-controlled studies compared variable doses of inhaled corticosteroid use and aimed to assess the efficacy and safety over 24 weeks in COPD patients. ${ }^{36,37}$ Doses for inhaled FF ranged from as high as $200 \mu \mathrm{g}$ to as low as $50 \mu \mathrm{g}$ and were combined with a set dose of VI at $25 \mu \mathrm{g}$. Subjects $(\mathrm{N}=1,224$ and $\mathrm{N}=1,030)$ with moderate-to-severe COPD experienced significant $(P<0.001) \mathrm{FEV}_{1}$ improvements (range of increase 103-209 mL) for all FF doses combined with VI $25 \mu \mathrm{g}$ when compared to placebo, but no difference was found when comparing inhaled FF/VI $200 \mu \mathrm{g} / 25 \mu \mathrm{g}$ versus FF/VI $100 \mu \mathrm{g} / 25 \mu \mathrm{g}$ treatments. ${ }^{36,37}$ As a result of this and similar data, inhaled FF/VI is FDA-approved for once-daily maintenance treatment and prevention of exacerbations of COPD using a combination multi-dose, dry-powder inhalation device containing FF $100 \mu \mathrm{g}$ and VI $25 \mu \mathrm{g}$. Evidence from these studies as well as others ${ }^{38,39}$ suggests that the combination FF/VI once-a-day inhaler offers an effective alternative to other available twice-daily dosing ICS/LABA combination inhalers (Table 1) for the treatment of COPD.

\section{Efficacy of FF and VI in asthma}

Although the initial studies performed for inhaled FF/VI were in COPD patients, it is obvious from the individual data on $\mathrm{FF}$ and VI in asthma that this combination of ICS/LABA therapy could also be applied to the treatment of asthma. Combination inhaled ICS/LABA therapy continues to be common in the treatment of persistent asthma, due to improved adherence as well as convenience. ${ }^{8,9} \mathrm{~A}$ recent randomized, double-blind study consisting of 806 patients compared the efficacy of inhaled FF/VI $100 \mu \mathrm{g} / 25 \mu \mathrm{g}$ administered once daily with FP/ SAL $250 \mu \mathrm{g} / 50 \mu \mathrm{g}$ administered twice daily over 24 weeks in patients aged greater than 12 years with persistent asthma that was poorly controlled on medium doses of ICS alone. ${ }^{40}$ The efficacy of once-daily FF/VI was similar to that of twice-daily $\mathrm{FP} / \mathrm{SAL}$ in improving lung function in these patients. Over the 24-week trial, the observed 0 - to 24-hour weighted mean $\mathrm{FEV}_{1}$ improvement over baseline was $341 \mathrm{~mL}$ for FF/VI and $377 \mathrm{~mL}$ for FP/SAL (adjusted treatment differences $-37 \mathrm{~mL}$; 95\% CI: -88 to $15 \mathrm{~mL} ; P=0.162) .{ }^{40}$ There were no differences in asthma exacerbation between the groups $(3 \% \mathrm{FP} / \mathrm{SAL}$ versus $2 \% \mathrm{FF} /$ VI). ${ }^{41}$ No differences were found in baseline Asthma Quality of Life +12 Questionnaire, Asthma Control Test, and European Quality of Life-5 Dimensions asthma health outcomes assessments between the two treatments. Both the FF/VI and the FP/ SAL groups showed improvement from baseline in the Asthma Quality of Life + 12 Questionnaire, Asthma Control Test, and the European Quality of Life-5 Dimensions asthma health assessments, with no difference seen between treatment groups. ${ }^{40}$

Another randomized, multicenter, double-blind study conducted between June 2010 and October 2011 at 63 centers in six countries (Germany, Japan, Poland, Romania, Russia, and the USA) compared the efficacy and safety of once-daily inhaled FF/VI $200 \mu \mathrm{g} / 25 \mu \mathrm{g}$ to once-daily inhaled FF $200 \mu \mathrm{g}$ or twicedaily inhaled FP $500 \mu \mathrm{g}$ in 586 patients older than 12 years of age with moderate-to-severe persistent asthma, in whom a significantly greater improvement in lung function was observed with FF/VI versus either FF alone or FP alone. ${ }^{42}$ Trough FEV at week 24 was improved with all therapies compared to baseline, with FF/VI patients showing a $394 \mathrm{~mL}$ improvement, FF patients a $201 \mathrm{~mL}$ improvement, and FP patients a $183 \mathrm{~mL}$ improvement in $\mathrm{FEV}_{1}$. When the improvement in $\mathrm{FEV}_{1}$ seen with daily FF/VI was compared to daily FF alone, a $193 \mathrm{~mL}$ (95\% CI: 108-277; $P<0.001)$ difference was seen. When daily $\mathrm{FF} / \mathrm{VI}$ improvement $\mathrm{FEV}_{1}$ was compared to twice-daily FP, a 210 mL (95\% CI: 127-294; $P<0.001)$ difference was seen. Improvement in rescue-free 24-hour periods was seen with FF/VI compared to FF alone. All treatments were generally well tolerated with no safety signals observed. ${ }^{42}$ This study 
demonstrated the benefit of once-daily inhaled combined FF/ VI compared to once-daily inhaled FF or twice-daily inhaled FP alone in patients with moderate-to-severe asthma.

In a crossover study of 52 subjects with mild asthma, inhaled FF/VI $100 \mu \mathrm{g} / 25 \mu \mathrm{g}$ and inhaled FF $100 \mu \mathrm{g}$ alone were dosed once daily in the evening for 28 days and compared to placebo to evaluate their capacity to provide bronchoprotection against early asthmatic response (EAR) and airway hyperresponsiveness (AHR) stimulated by an inhaled allergen challenge. ${ }^{41}$ Bronchoprotection against EAR was assessed by change from post-saline baseline weighted mean $\mathrm{FEV}_{1}$ for the first 2 hours post-allergen challenge on day 29 (22- to 23-hour post-final dose on day 28). The EAR was also assessed using maximum percent decrease from post-saline baseline and minimum absolute $\mathrm{FEV}_{1}$. Both $\mathrm{FF} / \mathrm{VI}$ and FF significantly suppressed the EAR to an allergen challenge relative to placebo. Allergen challenge caused reductions of $\mathrm{FEV}_{1}$ between 0 and 2 hours of $1.091 \mathrm{~L}(95 \% \mathrm{CI}$ : $1.344-0.837$ ) for placebo, $0.826 \mathrm{~L}$ (95\% CI: $1.070-0.581)$ for FF, 0.955 L (95\% CI: 1.209-0.702) for VI, and 0.614 L (95\% CI: $0.858-0.370$ ) for combined FF/VI. Measurements of AHR 24 hours after allergen challenge were significantly better with both FF/VI and FF compared to placebo. The use of FF/VI was superior to both $\mathrm{FF}$ and VI. ${ }^{41}$ The AHR was significantly reduced with FF/VI and FF compared to placebo. Inhaled FF/VI was superior to both $\mathrm{FF}$ and placebo. ${ }^{41}$

A randomized, double-blind variable-duration (24-78 weeks) trial comprising 2,019 patients aged $\geq 12$ years who had had one or more asthma exacerbations in the previous year compared the effects of inhaled FF $100 \mu \mathrm{g} / \mathrm{VI} 25 \mu \mathrm{g}$ once daily to inhaled FF $100 \mu \mathrm{g}$ once daily on the frequency of asthma exacerbations. ${ }^{43}$ The use of FF/VI demonstrated a rate reduction of $25 \%$ (95\% CI: $5 \%-40 \%)$, compared to $\mathrm{FF}$ alone. Once-daily inhaled FF/VI reduced the risk of severe asthma exacerbations (hazard ratio 0.75 ; 95\% CI: $0.642-0.985$ ) and improved lung function compared to inhaled $\mathrm{FF}$ alone, with excellent tolerability. ${ }^{43}$ In another study, both morning and evening once-daily dosing of inhaled FF $100 \mu \mathrm{g} / \mathrm{VI} 25 \mu \mathrm{g}$ produced comparable improvements in lung function in subjects $(\mathrm{N}=26)$ with persistent asthma after 14 days. ${ }^{44}$ The difference in weighted mean $\mathrm{FEV}_{1}$ from placebo was $377 \mathrm{~mL}$ (95\% CI: 293-507) for morning FF/VI and $422 \mathrm{~mL}$ (95\% CI: 337-507) for evening FF/VI dosing. No significant difference was seen in weighted mean $\mathrm{FEV}_{1}$ between morning and evening dosing of FF/VI ( $-44 \mathrm{~mL}, 95 \% \mathrm{CI}:-125$ to +36$)$. Consistent with other reports, the fixed combination of FF/VI once daily appears to be more effective than a similar once-daily inhaled dose of FF alone ${ }^{42}$, but clinical trials to date do not demonstrate a clear overall efficacy difference among ICS/LABA combinations approved for asthma therapy. ${ }^{45}$ Data support that inhaled FF/VI is just as efficacious as previous asthma regimens in terms of $\mathrm{FEV}_{1}$ and symptomatic relief in asthma, with the added benefit of it being a once-daily dosed inhaler. To date, this is the only combination ICS/LABA therapy that is dosed once daily with the potential to improve adherence in persistent asthma.

\section{Safety and adverse effects (AEs) of FF and VI}

The safety and adverse side effects of inhaled FF/VI can initially be evaluated by examining the effects of the individual components. Inhaled corticosteroids continue to be the anti-inflammatory therapy of choice in adult asthma due to their remarkable efficacy and apparent safety. ${ }^{9}$ The most commonly recognized AEs of ICS therapy are oropharyngeal candidiasis, dysphonia, and pneumonia. ${ }^{46}$ Other potential systemic effects of inhaled corticosteroids include adrenal suppression, bone loss, increased cataract formation, skin thinning, increased bruising, glucose/ metabolic changes, and behavioral abnormalities ${ }^{46}$ Some studies have reported mild AEs, including mouth ulcerations thrush and dysphonia, with ICS. ${ }^{38,39,49}$ Other frequent AEs with ICS include headache and upper respiratory infection. ${ }^{41}$

In one study, the frequency of adverse events, including upper respiratory infections, pneumonia, and urinary tract infections, was similar when inhaled FF/VI was compared to inhaled twice-daily FP/SAL ${ }^{40}$ Another study of asthma patients ${ }^{44}$ found oral candidiasis/oropharyngeal candidiasis was more common with FF/VI (6\%-7\%) than with FP (3\%) alone. Significant cortisol suppression was seen with FP compared to both FF/VI groups $(100 \mu \mathrm{g} / 25 \mu \mathrm{g}$ and $200 \mu \mathrm{g} / 25 \mu \mathrm{g})$ at weeks 12 and 28, but no suppression or differences were seen at week 52 for FF/VI $100 \mu \mathrm{g} / 25 \mu \mathrm{g}$ and for FF/VI $200 \mu \mathrm{g} / 25 \mu \mathrm{g}{ }^{44} \mathrm{~A}$ study of COPD patients showed no significant differences in end-oftreatment period 0 - to 24-hour weighted mean serum cortisol levels with inhaled FF/VI $50 \mu \mathrm{g} / 25 \mu \mathrm{g}, 100 \mu \mathrm{g} / 25 \mu \mathrm{g}$, or 200 $\mu \mathrm{g} / 25 \mu \mathrm{g}$ doses compared with placebo. ${ }^{38}$ The use of FF/VI dry-powder inhalers at doses of 100 or $200 \mu \mathrm{g} F \mathrm{~F}$ and $25 \mu \mathrm{g}$ VI was noninferior to placebo on hypothalamic-pituitary-adrenal axis function. ${ }^{47} \mathrm{~A}$ meta-analysis of eight studies concluded that hypothalamic-pituitary-adrenal alteration resulting in suppression of cortisol levels would routinely require FF levels several times higher than average clinically used doses. ${ }^{48}$ No significant changes were reported in non-fasting glucose, potassium, QT interval corrected using Fridericia's formula, or ophthalmic assessments. ${ }^{38,40,49}$ In a large, double-replicate, multicenter, randomized, double-blind, parallel-group COPD study comparing three strengths of FF/VI with one strength of VI, nasopharyngitis was the most frequently reported $\mathrm{AE}$ 
for both groups. ${ }^{39}$ Pneumonia and fractures were also reported more frequently with FF/VI than with VI alone. Similar to other ICS studies ${ }^{50,51}$ in COPD, a small increase in incidence of deaths from pneumonia was also noted in the inhaled FF/ VI group when compared with the inhaled VI group alone. ${ }^{39}$ More pneumonia-related deaths occurred in the inhaled FF/VI $200 \mu \mathrm{g} / 25 \mu \mathrm{g}$-treated group, which raises concern that a doserelated adverse event function exists. ${ }^{39}$ Similar consistent data in asthma studies demonstrating an increased risk for pneumonia are lacking.

The second component in the combination inhaler is a LABA, and commonly reported AEs for inhaled LABAs include arrhythmias, palpitations, tremor, headache, and metabolic effects that may also be dose related. The increase in death for monotherapy LABAs in asthma patients was reported in the Salmeterol Multicenter Asthma Research Trial (SMART) ${ }^{52}$ and in several systematic reviews. ${ }^{15,21}$ This resulted in an FDA "black box warning" for all inhaled LABAs and the recommendation of discontinuation of LABA therapy in well-controlled asthmatics. In asthma patients, no difference using 24-hour Holter monitoring was found in ventricular ectopy over 52 weeks between inhaled daily FF/VI (100 $\mu \mathrm{g} / 25 \mu \mathrm{g})$, daily FF/ VI $(200 \mu \mathrm{g} / 25 \mu \mathrm{g})$, and twice-daily FP $(500 \mu \mathrm{g}) .{ }^{49}$ Current data suggest that dry-powder inhaled FF/VI is well tolerated, with a favorable side effect profile, in the treatment of asthma.

\section{Conclusion}

Current guidelines for the treatment of persistent asthma offer management suggestions for the treatment of chronic asthma and stress the role of combined inhaled ICS/LABA in the treatment of persistent asthma. ${ }^{7-9}$ However, asthma remains poorly controlled in many patients, challenging physicians to reevaluate the current therapy, which should continue to be aimed at improving symptoms and in preventing asthma exacerbations. Approaches to maximizing medication adherence with personalized pharmacotherapy regimens that reduce asthma-related activity impairment and the risk of exacerbation in patients with persistent asthma is a major goal. Recent studies provide preliminary support for the use of inhaled FF/VI in the treatment of persistent asthma. It appears to be efficacious in patients with persistent asthma, with similar AEs to previous twice-daily inhaled ICS/LABA treatment options and with the added benefit of being a once-daily dosed inhaler. The excellent patient tolerability of inhaled FF/VI along with a likely increase in medication adherence should improve asthma outcomes and help prevent acute severe exacerbations. There is limited current data on the long-term use of FF/VI in persistent asthma patients. To date, no data demonstrating the efficacy of FF/VI over other combined ICS/LABA products in persistent asthma patients exist. Cost and safety data also remain limited in the asthma population, but the extensive data in COPD patients is reassuring.

\section{Disclosure}

TEAlbertson has spoken for GlaxoSmithKline regarding COPD. The authors report no other conflicts of interest in this work.

\section{References}

1. Barnett SB, Nurmagambetov TA. Costs of asthma in the United States: 2002-2007. J Allergy Clin Immunol. 2011;127(1):145-152.

2. Shams MR, Fineman SM. Asthma adherence: how can we help our patients do it better? Ann Allergy Asthma Immunol. 2014;112(1): 9-12.

3. Richardson K, Kenny RA, Peklar J, et al. Agreement between patient interview data on prescription medication use and pharmacy records in those aged older than 50 years varied by therapeutic group and reporting of indicated health conditions. J Clin Epidemiol. 2013;66:1308-1316.

4. Ingersoll KS, Cohen J. The impact of medication regimen factors on adherence to chronic treatment: a review of literature. J Behav Med. 2008;31(3):213-224.

5. Coleman CI, Limone B, Sobieraj DM, et al. Dosing frequency and medication adherence in chronic disease. $J$ Manag Care Pharm. 2012;18(7):527-539.

6. Albertson TE, Schivo M, Zeki AA, et al. The pharmacological approach to the elderly COPD patient. Drugs Aging. 2013;30(7):479-502.

7. Louie S, Zeki AA, Schivo M, et al. The asthma-chronic obstructive pulmonary disease overlap syndrome: pharmacotherapeutic considerations. Expert Rev Clin Pharmacol. 2013;6(2):197-219.

8. Elward KS, Pollart SM. Medical therapy for asthma: updates from the NAEPP Guidelines. Am Fam Physician. 2010;82(10):1242-1251.

9. Urbano FL. Review of the NAEPP 2007 Expert Panel Report (EPR-3) on Asthma Diagnosis and Treatment Guidelines. J Manag Care Pharm. 2008;14(1):41-49.

10. Albertson TE, Schivo M, Gidwani N, et al. Pharmacotherapy of critical asthma syndrome: current and emerging therapies. Clin Rev Allergy Immunol. Epub November 2, 2013.

11. Crim C, Pierre LN, Daley-Yates PT. A review of the pharmacology and pharmacokinetics of inhaled fluticasone propionate and mometasone furoate. Clin Ther. 2001;23(9):1339-1354.

12. Raissy HH, Kelly HW, Harkins M, Szefler SJ. Inhaled corticosteroids in lung diseases. Am J Respir Crit Care Med. 2013;187(8):798-803.

13. Szefler SJ, Martin RJ, King TS, et al; Asthma Clinical Research Network of the National Heart Lung, and Blood Institute. Significant variability in response to inhaled corticosteroids for persistent asthma. J Allergy Clin Immunol. 2002;109(3):410-418.

14. Martin RJ, Szefler SJ, King TS, et al; National Heart, Lung, and Blood Institute's Asthma Clinical Research Center. The Predicting Response to Inhaled Corticosteroid Efficacy (PRICE) trial. J Allergy Clin Immunol. 2007;119(1):73-80.

15. Shepherd J, Rogers G, Anderson R, et al. Systematic review and economic analysis of the comparative effectiveness of different inhaled corticosteroids and their usage with long-acting beta2 agonists for the treatment of chronic asthma in adults and children aged 12 years and over. Health Technol Assess. 2008;12(19):iii-iv, 1-360.

16. Woodcock A, Bleecker ER, Busse WW, et al. Fluticasone furoate: once-daily evening treatment versus twice-daily treatment in moderate asthma. Respir Res. 2011;12:160.

17. Busse WW, Bleecker ER, Bateman ED, et al. Fluticasone furoate demonstrates efficacy in patients with asthma symptomatic on medium doses of inhaled corticosteroid therapy: an 8-week, randomised, placebocontrolled trial. Thorax. 2012;67(1):35-41.

18. Medley H, Orozco S, AllenA. Efficacy and safety profile of fluticasone furoate administered once daily in the morning or evening: a randomized, doubleblind, double-dummy, placebo-controlled trial in adult and adolescent patients with persistent bronchial asthma. Clin Ther. 2012; 34(8):1683-1695. 
19. Panina-Bordignon P, Mazzeo D, Lucia PD, et al. Beta2-agonists prevent Th1 development by selective inhibition of interleukin 12. J Clin Invest. 1997;100(6):1513-1519.

20. Aggarwal P, Bhoi S. Comparing the efficacy and safety of two regimens of sequential systemic corticosteroids in the treatment of acute exacerbation of bronchial asthma. J Emerg Trauma Shock. 2010;3(3):231-237.

21. Kramer JM. Balancing the benefits and risks of inhaled long-acting beta-agonists - the influence of values. N Engl J Med. 2009;360(16): 1592-1595.

22. Bacharier LB. Step-down therapy in asthma: a focus on treatment options for patients receiving inhaled corticosteroids and long-acting beta-agonist combination therapy. Allergy Asthma Proc. 2012;33(1): 13-18.

23. Sykes DA, Charlton SJ. Slow receptor dissociation is not a key factor in the duration of action of inhaled long-acting beta2-adrenoceptor agonists. Br J Pharmacol. 2012;165(8):2672-2683.

24. Patel S, Summerhill S, Stanley M, Perros-Huguet C, Trevethick MA. The reassertion profiles of long acting beta2-adrenoceptor agonists in the guinea pig isolated trachea and human recombinant $\beta 2$-adrenoceptor. Pulm Pharmacol Ther. 2011;24(2):247-255.

25. Lötvall J, Bateman ED, Bleecker ER, et al. 24-h duration of the novel LABA vilanterol trifenatate in asthma patients treated with inhaled corticosteroids. Eur Respir J. 2012;40(3):570-579.

26. Procopiou PA, Barrett VJ, Bevan NJ, et al. Synthesis and structureactivity relationships of long-acting beta 2 adrenergic receptor agonists incorporating metabolic inactivation: an antedrug approach. $\mathrm{J} \mathrm{Med}$ Chem. 2010;53(11):4522-4530.

27. Kempsford R, Norris V, Siederer S. Vilanterol trifenatate, a novel inhaled long-acting beta2 adrenoceptor agonist, is well tolerated in healthy subjects and demonstrates prolonged bronchodilation in subjects with asthma and COPD. Pulm Pharmacol Ther. 2013;26(2):256-264.

28. Ducharme FM, Ni Chroinin M, Greenstone I, Lasserson TJ. Addition of long-acting beta2-agonists to inhaled steroids versus higher dose inhaled steroids in adults and children with persistent asthma. Cochrane Database Syst Rev. 2010;(4):CD005533.

29. Lazarus SC, Boushey HA, Fahy JV, et al; Asthma Clinical Research Network for the National Heart, Lung, and Blood Institute. Long-acting beta2-agonist monotherapy vs continued therapy with inhaled corticosteroids in patients with persistent asthma: a randomized controlled trial. JAMA. 2001;285(20):2583-2593.

30. Bender B, Milgrom H, Apter A. Adherence intervention research: what have we learned and what do we do next? J Allergy Clin Immunol. 2003;112(3):489-494.

31. Bender B, Milgrom H, Rand C. Nonadherence in asthmatic patients: is there a solution to the problem? Ann Allergy Asthma Immunol. 1997;79(3):177-185; quiz 185-186.

32. Onyirimba F, Apter A, Reisine S, et al. Direct clinician-to-patient feedback discussion of inhaled steroid use: its effect on adherence. Ann Allergy Asthma Immunol. 2003;90(4):411-415.

33. Chmelik F, Doughty A. Objective measurements of compliance in asthma treatment. Ann Allergy. 1994;73(6):527-532.

34. Lindsay JT, Heaney LG. Nonadherence in difficult asthma - facts, myths, and a time to act. Patient Prefer Adherence. 2013;7:329-336.

35. Lötvall J, Bakke PS, Bjermer L, et al. Efficacy and safety of 4 weeks' treatment with combined fluticasone furoate/vilanterol in a single inhaler given once daily in COPD: a placebo-controlled randomised trial. BMJ Open. 2012;2(1):e000370.
36. Martinez FJ, Boscia J, Feldman G, et al. Fluticasone furoate/vilanterol $(100 / 25 ; 200 / 25 \mu \mathrm{g})$ improves lung function in COPD: a randomised trial. Respir Med. 2013;107(4):550-559.

37. Kerwin EM, Scott-Wilson C, Sanford L, et al. A randomised trial of fluticasone furoate/vilanterol $(50 / 25 \mu \mathrm{g} ; 100 / 25 \mu \mathrm{g})$ on lung function in COPD. Respir Med. 2013;107(4):560-569.

38. Boscia JA, Pudi KK, Zvarich MT, Sanford L, Siederer SK, Crim C. Effect of once-daily fluticasone furoate/vilanterol on 24-hour pulmonary function in patients with chronic obstructive pulmonary disease: a randomized, three-way, incomplete block, crossover study. Clin Ther. 2012;34(8):1655-1666.

39. Dransfield MT, Borbeau J, Jones PW, et al. Fluticasone furoate and vilanterol for COPD. Lancet Respir Med. 2013;1(3):210-223.

40. Woodcock A, Bleecker ER, Lötvall J, et al. Efficacy and safety of fluticasone furoate/vilanterol compared with fluticasone propionate/ salmeterol combination in adult and adolescent patients with persistent asthma: a randomized trial. Chest. 2013;144(4):1222-1229.

41. Oliver A, Bjermer L, Quinn D, et al. Modulation of allergen-induced bronchoconstriction by fluticasone furoate and vilanterol alone or in combination. Allergy. 2013;68(9):1136-1142.

42. O’Byrne PM, Bleecker ER, Bateman ED, et al. Once-daily fluticasone furoate alone or combined with vilanterol in persistent asthma. Eur Respir J. 2014;43(3):773-782.

43. Bateman ED, O'Byrne PM, Busse WW, et al. Once-daily fluticasone furoate $(\mathrm{FF}) /$ vilanterol reduces risk of severe exacerbations in asthma versus FF alone. Thorax. Epub November 19, 2013.

44. Kempsford RD, Oliver A, Bal J, Tombs L, Quinn D. The efficacy of once-daily fluticasone furoate/vilanterol in asthma is comparable with morning or evening dosing. Respir Med. 2013;107(12):1873-1880.

45. Tamm M, Richards DH, Beghe B, Fabbri L. Inhaled corticosteroid and long-acting $\beta 2$-agonist pharmacological profiles: effective asthma therapy in practice. Respir Med. 2012;106 Suppl 1:S9-S19.

46. Hanania NA, Chapman KR, Kesten S. Adverse effects of inhaled corticosteroids. Am J Med. 1995;98(2):196-208.

47. Allen A, Schenkenberger I, Trivedi R, et al. Inhaled fluticasone furoate/ vilanterol does not affect hypothalamic-pituitary-adrenal axis function in adolescent and adult asthma: randomised, double-blind, placebocontrolled study. Clin Respir J. 2013;7(4):397-406.

48. Allen A. The relationship between fluticasone furoate systemic exposure and cortisol suppression. Clin Pharmacokinet. 2013;52(10):885-896.

49. Busse WW, O’Byrne PM, Bleecker ER, et al. Safety and tolerability of the novel inhaled corticosteroid fluticasone furoate in combination with the $\beta 2$ agonist vilanterol administered once daily for 52 weeks in patients $\geq 12$ years old with asthma: a randomised trial. Thorax. 2013;68(6):513-520.

50. Mattishent K, Thavarajah M, Blanco P et al. Meta-Review: Adverse Effects of Inhaled Corticosteroids Relevant to Older Patients. Drugs. 2014. In press 2014

51. Kew KM, Seniukovich A. Inhaled steroids and risk of pneumonia for chronic obstructive pulmonary disease. Cochrane Database of Systematic Reviews. 2014:3:CD010115.

52. Nelson HS, Weiss ST, Bleecker ER, Yancey SW, Dorinsky PM; SMART Study Group. The Salmeterol Multicenter Asthma Research Trial: a comparison of usual pharmacotherapy for asthma or usual pharmacotherapy plus salmeterol. Chest. 2006;129(1):15-26.

Journal of Asthma and Allergy

\section{Publish your work in this journal}

The Journal of Asthma and Allergy is an international, peer-reviewed open-access journal publishing original research, reports, editorials and commentaries on the following topics: Asthma; Pulmonary physiology; Asthma related clinical health; Clinical immunology and the immunological basis of disease; Pharmacological interventions and

new therapies. Issues of patient safety and quality of care will also be considered. The manuscript management system is completely online and includes a very quick and fair peer-review system, which is all easy to use. Visit http://www.dovepress.com/testimonials.php to read real quotes from published authors. 